Research report

\title{
Processing semantic anomalies in two languages: an electrophysiological exploration in both languages of Spanish-English bilinguals
}

\author{
Eva M. Moreno ${ }^{\mathrm{a}}$, Marta Kutas ${ }^{\mathrm{a}, \mathrm{b}, *}$ \\ ${ }^{a}$ Department of Cognitive Science, University of California, San Diego, CA, United States \\ ${ }^{\mathrm{b}}$ Department of Neurosciences, University of California, San Diego, CA, United States
}

Accepted 12 August 2004

Available online 28 September 2004

\begin{abstract}
The latency of the brain response to semantic anomalies (N400 effect) has been found to be longer in a bilingual's second language (L2) than in their first language (L1) and/or to that seen in monolinguals. This has been explained in terms of late exposure to L2, although age of exposure and language proficiency are often highly correlated. We thus examined the relative contributions of these factors not only in L2 but also in L1 in a group of Spanish-English bilinguals for whom age of exposure and language proficiency were not highly correlated by recording event-related brain potentials (ERPs) to semantically congruous/incongruous words completing written sentences. We also divided our bilinguals into a Spanish-dominant subset who had late exposure and reduced vocabulary proficiency [as measured by Boston Naming Test (BNT) and Verbal Fluency Scores] in L2 (English) relative to L1 (Spanish) and an English-dominant group who had early exposure to both their languages although greater proficiency in English than in Spanish. In both groups, the N400 effect was significantly later in the nondominant than the dominant language. Although this slowing could be due to late exposure to English in the Spanish-dominant group, late exposure cannot explain the slowing in Spanish in the English-dominant group. Overall, we found that vocabulary proficiency and age of exposure are both important in determining the timing of semantic integration effects during written sentence processing - with vocabulary proficiency predicting the timing of semantic analysis in L1 and both age of exposure and language proficiency, although highly correlated, making additional small but uncorrelated contributions to the speed of semantic analysis/ integration in L2.
\end{abstract}

(C) 2004 Elsevier B.V. All rights reserved.

Theme: Neural basis of behavior

Topic: Cognition

Keywords: Bilingualism; Event-related potentials; Sentence processing; N400; Second language; Concreteness effects

\section{Introduction}

A significant number of people know two or more languages. In fact, one in three of the world's population routinely uses two or more languages for work, family life and leisure [53]. The proportion of bilinguals in the United States, while less, is still a nontrivial number: according to

* Corresponding author. Department of Cognitive Science, UCSD, 9500 Gilman Dr., La Jolla, CA 92093-0515, United States. Tel.: +1 858534 2440; fax: +1 8585341128

E-mail address: kutas@cogsci.ucsd.edu (M. Kutas). the 2000 census, nearly 1 in 5 people, or 47 million U.S. residents age 5 and older, speak a language other than English at home, the most common being Spanish (28.1 million). Among U.S. residents who speak Spanish at home, just over half report also speaking English "very well" [46]. Indeed, "balanced bilinguals"-i.e., individuals that are equally proficient in both of their languages - are a rare breed. A multilingual speaker typically uses his/her different languages for different purposes and more often than not does not possess the same level and/or type of proficiency in both languages, typically being more dominant in one relative to the other [53]. There are many reasons for this 
proficiency imbalance, including when each language was learned, how it was learned, how often it is used, and the circumstances of its use, among others.

Research with a variety of methodologies has shown age of acquisition or exposure to be a crucial variable for the degree of proficiency attained in a second language (L2; e.g., Refs. $[6,16])$. It is generally assumed that the earlier that a language is acquired, the higher the level of proficiency eventually attained by the user, especially with regard to the syntactic (although also for the lexicosemantic) aspects of language [52]. Age of exposure/ acquisition, however, cannot be the whole story given the phenomenon of first language forgetting, loss, or attritionthat is, the decline in native or first language (L1) proficiency in immigrant populations immersed in a second language environment. First language forgetting - with vocabulary items generally being the first signs of lossusually derives from lost or restricted contact of bilinguals with speakers of their first language [37]. Prolonged use and continued acquisition/learning, probably in multiple settings, thus seems to be important for maintaining one's first language, even when initial exposure and acquisition occur quite early. A similar tension between the role of age of exposure and language experience has arisen in the neuroimaging literature with respect to functional organization of the two languages of a bilingual (see Ref. [1] for a review, $[19,42])$.

Here, we aim to explore semantic processing in both languages of Spanish-English bilinguals with varying language proficiencies in both L1 and L2 who were exposed to L1 quite early (if not from birth) but who vary considerably in their age of exposure to L2. Our analysis makes use of a component of the event-related brain potential (ERP) - the N400 - that is known to vary in amplitude with semantic and lexical manipulations (see Ref. [25] for a review). Numerous studies in many different languages have shown that the brain's response to a semantically incongruent word is characterized by a greater negativity, 200-500 ms postword onset compared to that for a semantically congruent word, whether written or spoken; in monolinguals, this $\mathrm{N} 400$ has a centro-parietal maximum, with a slight right hemisphere bias. This N400 semantic congruity effect (incongruent minus congruent ERP) varies with ease of contextual (semantic) integration: the more difficult it is to integrate the eliciting word with the representation of the ongoing context, the larger the associated N400 with all other factors (frequency, repetition, imageability, word class) held constant.

The latency of the N400 congruity effect is remarkably stable, ranging from 250 to $600 \mathrm{~ms}$ and peaking around 400 $\mathrm{ms}$ for the average undergraduate in his/her $20 \mathrm{~s}$, and increasing by approximately $1.5-2.1 \mathrm{~ms} /$ year [27]. Within young monolingual adults, the timing of the visual N400 congruity effect is affected primarily by the rate of word presentation during word-by-word reading. The N400 elicited by semantic anomalies in moderate-to-strongly constraining sentences peaks approximately $80-100 \mathrm{~ms}$ later $(\sim 500 \mathrm{~ms})$ for fast (10 words/s) versus slower (one word/700 ms) presentation rates [24]. The N400 congruity effect also has been found to have a longer latency in bilinguals processing their less-dominant language [3], the one to which they were exposed later [28,52], or even to their first language when compared to monolinguals [3].

Ardal et al. [3] presented English and French sentences, half ending with a semantic anomaly, to a group of bilinguals fluent in French and English, most of whom had English as a second language (L2). Participants read the sentences one word at a time for comprehension. On average, the latency of the N400 peak was approximately $40 \mathrm{~ms}$ shorter in monolinguals (in English) than in the bilingual's L2, and $\sim 17-37$ ms shorter in L1 than L2 within bilinguals. Bilinguals' ERPs also were characterized by reduced frontal negativities in L2 relative to L1. N400s did not differ for participants matched on language fluency but differing in age of acquisition for L2 (acquiring L2 prior to age 11 vs. during or after adolescence), leading the authors to conclude that current usage and fluency more than age of acquisition were the primary determinants of the timing and amplitude of the congruity N400. They also noted that the N400 in monolinguals was right lateralized, while in bilinguals, it was left lateralized.

Different conclusions were reached by Weber-Fox and Neville [52] who compared ERPs of English monolinguals and Chinese-English bilinguals as they judged the "goodness" of English sentences, some of which contained either semantic or syntactic violations. The various groups did not differ in N400 amplitude according to their age of exposure to English, although monolinguals had reliably earlier congruity N400s than bilinguals whose initial L2 exposure (English) was between 11 and 13 years $(431 \mathrm{~ms})$ or after age $16(431 \mathrm{~ms})$; all other bilinguals with earlier exposure to L2 (1-3, 4-6 and 7-10 years of age) had N400 peak latencies comparable to those of the English monolinguals $(407 \mathrm{~ms})$. The authors concluded that late exposure to L2 (>10 years) significantly slows the speed of semantic analysis, although regression analyses on N400 peak latencies showed significant linear relationships with both age of exposure $(r=0.31, p=0.015)$ and years of language experience $(r=-0.25, p=0.05)$, with no reliable difference between these two predictors $(t=0.73$, n.s.). Although language fluency was not measured, self-reported L2 proficiency suggests that earlier exposure was well correlated with higher proficiency in L2, rendering it impossible to determine the extent to which age of exposure and not fluency was the relevant variable determining N400 latency. The authors argued for age of acquisition by pointing out that although the 16-year-old-and-older group had lower overall L2 proficiency levels than the 11- to 13-year-olds, both showed equivalent delays in N400 latency relative to monolingual groups; implicit in this argument is the notion of a critical age or threshold (perhaps around 10 years of age) after which fine differences in proficiency can no 
longer compensate for the costs of late L2 exposure. However, even in this case, self-rated proficiency in reading (the very skill tapped by the ERP experiment) did not distinguish these two late L2 exposure groups. Finally, in this study, bilinguals exposed to L2 after age 3, did not show the typical right $\mathrm{N} 400$ lateralization.

Hahne and Friederici [14] compared auditory sentence comprehension and grammaticality judgment in native Japanese speakers who learned German (L2) after the age of 18 with that of native German speakers. Both groups showed a centro-parietal N400 effect, although it lasted $\sim 400 \mathrm{~ms}$ longer in the bilinguals. Contextual integration was presumably prolonged due to less certain vocabulary knowledge and use by the bilinguals, although this hypothesis does not readily fit with the larger positivity $(500-1100 \mathrm{~ms})$ to semantically correct sentences in the bilinguals compared to monolinguals; the authors, however, attributed this difference in positivity to greater difficulty of syntactic integration for the bilinguals in L2.

A similar study by Hahne [13] compared 16 native Russians who learned German after the age of 10 to native German speakers. Semantic violations elicited an $\mathrm{N} 400$ in both groups and group differences were again observed for the correct but not semantically incorrect sentences, although not in the late positivity (500-1200 $\mathrm{ms})$. Rather, the N400 to correct sentence endings was more pronounced, delayed by $\sim 100 \mathrm{~ms}$, and extended to frontal electrode sites for the bilinguals. The congruity effect was thus smaller in the bilinguals and reached its peak earlier in the native German speakers (550 vs. 750 $\mathrm{ms})$. Age of exposure and L2 proficiency were highly correlated with each other and L1 processing in the bilinguals was not assessed.

Proverbio et al. [43] focused on the brain topography of ERPs - in Italian-speaking monolinguals and SlovenianItalian bilinguals who had early exposure to and high proficiency in L2 - collected as they read syntactically and/ or semantically incorrect sentences in Italian. Monolinguals showed the typical right lateralization in the N400 region (350-450 ms) while the bilinguals showed larger N400s over the left hemisphere.

In summary, the various investigations of N400 effects in bilinguals differ in the specific languages compared, the modality (visual vs. auditory) of presentation, the task requirements besides comprehension, and, arguably most importantly in the characteristics of the participant's bilingualism (age of exposure, L2 proficiency). Nevertheless, one of the more consistent findings is a relative delay in the latency of the N400 effect for the less fluent or later acquired language [3,52]. The relative importance of age of exposure and/or language fluency on this "slowing" of the brain's response to semantic anomalies (N400 latency) in a bilingual's second language (L2), however, remains uncertain. Ardal et al. examined bilinguals who varied in their age of exposure to L2 (early vs. late) but were highly fluent in both languages.
They concluded that fluency was the most important factor, especially when comparing across the two languages of a bilingual. Weber-Fox and Neville, on the other hand, examined bilinguals who varied in their exposure to L2 (from 1 to over 16 years) but also in their L2 proficiency, and argued for the criticality of age of exposure. In their sample, however, age of exposure and L2 proficiency were highly correlated; they did not assess L1 processing. We thus examined semantic processing in both languages of Spanish-English bilinguals who did not vary much in their age of exposure to L1, did vary significantly in their age of exposure to L2, and importantly also varied considerably in their vocabulary proficiencies in both L1 and L2 with the aim of decoupling the contributions of age of exposure and language proficiency insofar as possible.

Specifically, we measured the brain's responses to semantically congruent and semantically anomalous sentence final words in English and in Spanish from 47 Spanish-English bilinguals. We capitalized on the fact that many bilinguals in Southern California (20 in our sample) have a relatively early (often simultaneous) exposure to both Spanish and English, although generally become more proficient (dominant) in one of them (English), still continue to use the other (Spanish) on a daily basis. In this group in particular, we could assess the importance of language proficiency in L1 when it is uncorrelated with age of acquisition. If, as argued by Ardal et al., relative language proficiency is the primary determinant of language processing efficacy, then we would expect the N400 congruity effect to be delayed in their nondominant (Spanish) relative to their dominant (English) language. However, if early exposure alone or in combination with continued use is key to determining the speed of language processing, then this subgroup's early exposure to Spanish might effectively insulate their N400s from slowing even in the face of reduced vocabulary proficiency (which might be reflected in N400 amplitude modulations). Although no researchers have explicitly made this prediction, it is a reasonable inference from any position that argues for a critical period in language acquisition [31]. We also assessed semantic processing in a more typical group of 20 Spanish-English bilinguals in whom age of exposure and proficiency in L2 are highly correlated, namely, native, Spanish-dominant speakers with, on average, relatively later exposure and reduced proficiency in L2 (English). In this group, as well, we expected to find a longer latency N400 congruity effect in the nondominant versus the dominant language, as well as a significant correlation between age of acquisition and N400 latency in L2. In summary, then, we assessed semantic processing in the dominant and nondominant language in two subgroups of Spanish-English bilinguals (20 each) - one having late exposure and lower proficiency in English (as in WeberFox and Neville), and another having early exposure to both languages (English and Spanish), although more 
Table 1

Sentences and target final word examples

\begin{tabular}{|c|c|c|}
\hline & Congruent & Incongruent \\
\hline $\begin{array}{l}\text { He wondered if the storm } \\
\text { had done much ... }\end{array}$ & damage & children \\
\hline $\begin{array}{l}\text { Él se preguntaba si la } \\
\text { tormenta habría } \\
\text { causado muchos ... }\end{array}$ & daños & niños \\
\hline $\begin{array}{l}\text { It's hard to admit } \\
\text { when one is ... }\end{array}$ & wrong & tasty \\
\hline $\begin{array}{l}\text { Es duro reconocer } \\
\text { cuando uno está ... }\end{array}$ & equivocado & sabroso \\
\hline $\begin{array}{l}\text { When you go to bed } \\
\text { turn off the ... }\end{array}$ & lights & turtles \\
\hline $\begin{array}{c}\text { Cuando te vayas a la } \\
\text { cama apaga las ... }\end{array}$ & luces & tortugas \\
\hline $\begin{array}{l}\text { The athletes crossed } \\
\text { the finish ... }\end{array}$ & line & pepper \\
\hline $\begin{array}{l}\text { Los atletas cruzaron } \\
\text { la línea de ... }\end{array}$ & meta & pimienta \\
\hline
\end{tabular}

proficient in the vocabulary of one language (English) than the other (Spanish). We also assessed semantic processing in L1 and L2 of a subset of bilinguals $(N=31)$ drawn from these two dominance groups. In so doing, we aimed to dissociate the relative contributions of age of exposure and vocabulary proficiency to the "slowing", if any, of the brain response (N400) to semantic violations in L1, and to replicate the effects of these two factors on the N400 elicited by semantic violations in $\mathrm{L} 2$.

\section{Materials and methods}

\subsection{Materials}

Ninety-six highly contextually constrained English sentences (cloze probability of final word above $70 \%$ ) used previously with monolinguals $[26,33]$ were translated into Spanish by the first author (native speaker) and proofread by another Spanish speaker. Each sentence and its translation were duplicated to introduce a semantically incongruous final word in place of its semantically congruous ending. Incongruent endings were the same part of speech as the congruous ones but unrelated to the sentence context (see Table 1 for sample sentences). Sentence final words were equivalent in length and word frequency of usage across the two languages on average. English frequencies were extracted from Francis and Kucera's [10] database of over 1,014,000 entries, whereas Spanish frequencies were obtained from Alameda and Cuetos' [2] norms of over 2,000,000 entries (see Table 2). Sentences materials were divided in four experimental lists, such that no sentence context or target, English or Spanish, was repeated within a list. Each list contained a total of 96 sentences, half in English (48) and half in Spanish (48). Within each language set, half were semantically congruous (24) and half semantically incongruous (24). Sentence order was randomized within each language set on each list and then presented in counterbalanced language blocks. Participants were randomly assigned to one of the four lists.

\subsection{Procedure}

These sentence blocks were the final blocks of a larger study in which Spanish-English bilinguals were asked to read sentences for comprehension. The experiment was undertaken with written consent of each participant. After administration of Handedness [36] and Language History (Center for Research in Language, University of California, San Diego) questionnaires, participants read sentences in English and Spanish half of which ended in a language (code) switch on the sentence final word. A brief recognition test for these sentences followed. Participants were then asked to read for comprehension a series of sentences, none of which included any code switches, first in one language, then the other, and so on.

Sentences were presented in four blocks alternating between the two languages with the order of block presentation counterbalanced across participants. Each sentence was presented one word at a time in the middle of the screen followed at sentence end by 'Press to continue' or 'Presione para continuar', depending on the language of the block. Words were presented at a rate of 2/ $\mathrm{s}$ for $200 \mathrm{~ms}$ each, with the exception of the final word (500 ms).

Table 2

Mean word frequency and length across experimental conditions

\begin{tabular}{lcccc}
\hline & \multicolumn{2}{l}{ Congruent targets } & & \multicolumn{3}{l}{ Incongruent targets } \\
\cline { 2 - 3 } \cline { 5 - 6 } & English & Spanish & $6(1.6)$ & \multicolumn{2}{l}{ English } & Spanish \\
\hline Length & $4.8(1.4)$ & $182(303)$ & $5.3(1.5)$ & $6.1(1.4)$ \\
Absolute freq. & $102(186)$ & $0.009(0.015)$ & $0.0047(0.007)$ & $96.8(165)$ \\
\% Frequency & $0.010(0.018)$ & $0.0048(0.008)$ & $0.0048)$ \\
\hline
\end{tabular}

Standard deviations are shown in parenthesis. Absolute English frequencies extracted from Francis and Kucera [10]. Absolute Spanish frequencies extracted from Alameda and Cuetos [2]. The frequency percentage was estimated over a total of 1,014,000 entries for the English norms and a total of 2,000,000 entries on the Spanish norms. Although overall incongruent endings were of lower frequency than congruent endings, the congruent/incongruent frequency ratio was comparable across languages. 
Following the recording session, participants received a questionnaire about his/her impressions of the experimental session. For the second half of the experiment, they were specifically asked whether they found it harder and/or whether it took them more time to understand a sentence that did not make sense in one language than the other. Participants' vocabulary skills were then assessed by asking them to name the 60 line drawings of the Boston Naming Test (BNT) [17] first in one language and then in the other (order of language was counterbalanced across participants). BNT items are ordered by increasing difficulty from item 1 (bed) to item 60 (abacus). Kohnert et al. [21] found a positive correlation (although not a strict one-to-one mapping) between the degree of difficulty in English and in Spanish.

Participants were also administered the letter and category verbal fluency tests from the Multilingual Aphasia Examination battery in both languages in counterbalanced order across participants (MAE, MAE-S) $[5,44]$. In these, the participant is asked to produce all of the words that $\mathrm{s} / \mathrm{he}$ can think of beginning with the specified letter (F, A, S in English, and P, T, M in Spanish) or belonging to the specified category during a 60 -s interval for each letter or category (animals, fruits and vegetables; see Ref. [12]).

\subsection{EEG recording procedure}

Scalp electrical activity was recorded from 26 geodesically spaced tin electrodes embedded in an elastic cap referenced to the left mastoid. Electrodes placed on the outer canthus and infraorbital ridge of each eye were used to monitor blinks and horizontal eye movements. Electrode impedances were kept below $5 \mathrm{~K} \Omega$. Signals were amplified within a bandpass of 0.01 to $100 \mathrm{~Hz}$ and continuously digitized at $250 \mathrm{~Hz}$.

Data were re-referenced off-line to the average of the left and right mastoids. Trials contaminated by eye movements, excessive muscle activity, or amplifier blocking were rejected automatically (using thresholds set via visual inspection). Less than $3 \%$ of trials were lost due to such artifacts. In addition, $9 \%$ of trials containing blinks were corrected via a spatial filter algorithm [8]. A bandpass filter of 0.1 to $20 \mathrm{~Hz}$ was also applied to all data. ERPs were then computed for epochs extending from $100 \mathrm{~ms}$ before stimulus onset to $920 \mathrm{~ms}$ after stimulus onset. Artifact-free averaged ERPs to sentence final words were obtained for each type of target ending (congruent ending in English or Spanish, and semantic violation in English or Spanish) after subtraction of $100 \mathrm{~ms}$ prestimulus baseline.

\subsection{Participants}

Forty-seven Spanish-English bilingual speakers (31 women and 16 men) with mean age 26.5 (range 19 to 38) were paid for their participation in the study. Participants were residents of San Diego (often UCSD students or their partners) or Tijuana (also students) and were recruited through advertisements. Forty-six were right-handed and one was ambidextrous, according to Edinburgh Inventory [36]. Nine participants reported family history of lefthandedness or ambidextrousness.

Most participants (41 out of 47) were exposed to Spanish at birth, the remainder between 1 and 6 years $(N=4)$, or between 10 and 12 years $(N=2)$ of age. Participants varied more widely in their age of exposure to English: 11 participants were exposed to English at birth, 21 between 1 and 6 years, 12 between 7 and 14 years, and 3 after age 14 . Participants thus were grouped in several ways for analysis. The main analyses were based on each participant's difference in performance on the BNT in English and Spanish. Those with a difference of eight or less in the number of drawings correctly named in the two languages were considered as balanced in vocabulary performance ( 6 women and $1 \mathrm{man}$ ) and were not included in the analysis based on language dominance; of the remaining 40 participants, 20 were Spanish dominant (naming on average 21, range 12-33, more items in Spanish than in English) and 20 were English dominant (naming on average 22, range 11-42, more items in English than in Spanish). These two groups also differed substantially in their initial exposure to English, although all were "nearly native" in Spanish. More specifically, on average, the Spanishdominant group had a later exposure to L2 (12 of 20 were 10 years or older when first exposed to English), whereas all but one (exposed at age 4) of them were exposed to Spanish at birth. The English-dominant group, by contrast, had a relatively early exposure to both languages (17 of 20 were exposed to Spanish at birth and all were 6 years or younger when first exposed to English). Participants also were grouped according to self-reported native language (L1 vs. L2). The Language History Questionnaire also asked participants to estimate how often they used each of their languages with their (grand)parents, siblings, spouse/ intimates, children, friends, other relatives, and pets. The Spanish dominants reported using Spanish on average 81\% of the time, English $16 \%$ of the time, with a subset using a third or fourth language (Catalan, Galician, German) to speak to friends or family. On average, the English dominants used English 55\% of the time and Spanish $44 \%$ of the time, with a few also using a third language (French, Italian).

\section{Results}

3.1. Self-report on the difficulty/speed of reading incongruent sentences in both languages

Self-report on the ease of processing each language revealed that participants generally found it harder to 
process semantic anomalies in their nondominant language, albeit for different reasons. With regard to their perceived speed of processing in the two languages, Spanish dominants thought that it took them more time to realize that a sentence was nonsensical when it was in their nondominant language, while English dominants were almost equally divided between thinking that they were slower in their nondominant language (8 of 19) and thinking that it took them equal amounts of time in their two languages (11 of 19).

\subsection{Brain responses to semantic (in)congruity in dominant and nondominant language}

Fig. 1 shows grand average ERPs to the sentence final word of sentences that were either semantically congruent or incongruent for both the dominant and nondominant languages of the bilingual participants $(N=40)$. Relative to congruent endings, semantically incongruous endings elicited an enhanced centro-parietal negativity between 200 and $600 \mathrm{~ms}(\mathrm{~N} 400)$ in both the bilinguals' languages.

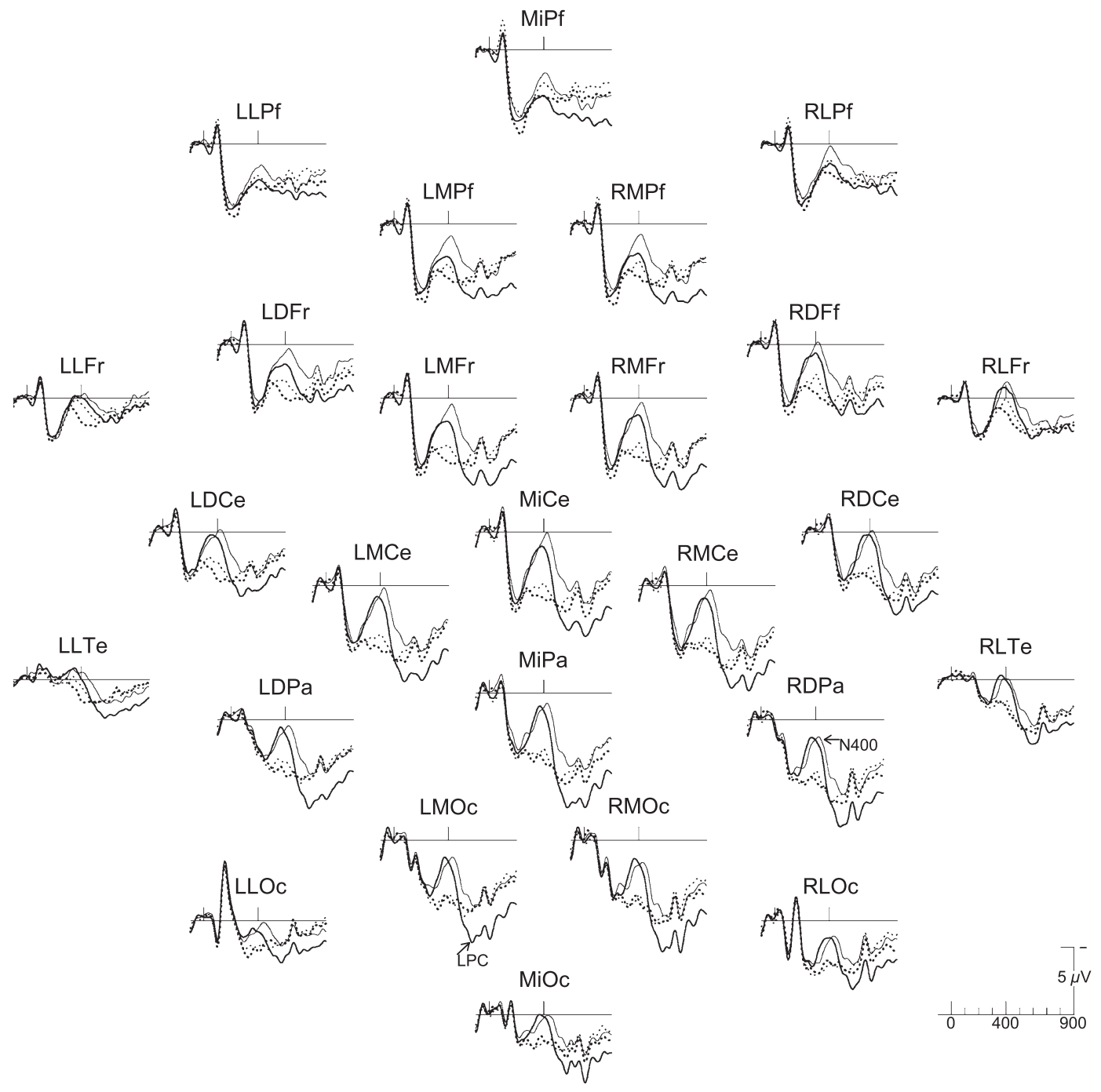

Congruent (Dominant Language)

Congruent (Non-dominant Language)

Semantic violation (Dominant Language)

Semantic violation (Non-dominant Language)

Fig. 1. Grand average ERPs to the sentence final word of sentences semantically congruent (dotted lines) or incongruent (solid lines) in both the dominant (thick lines) and nondominant (thin lines) of 40 bilingual participants. Channel arrangement represents a head view from the top. Each channel is labeled with first initial representing hemisphere $(\mathrm{L}=\mathrm{Left}, \mathrm{Mi}=$ Midline, $\mathrm{R}=$ Right), second representing laterality ( $\mathrm{L}=\mathrm{Lateral}, \mathrm{D}=\mathrm{Dorsal}, \mathrm{M}=\mathrm{Medial}$ ), and final two representing brain region $(\mathrm{Pf}=\mathrm{Prefrontal}, \mathrm{Fr}=\mathrm{Frontal}, \mathrm{Ce}=\mathrm{Central}, \mathrm{Pa}=\mathrm{Parietal}, \mathrm{Te}=$ Temporal, $\mathrm{Oc}=\mathrm{Occipital})$. 


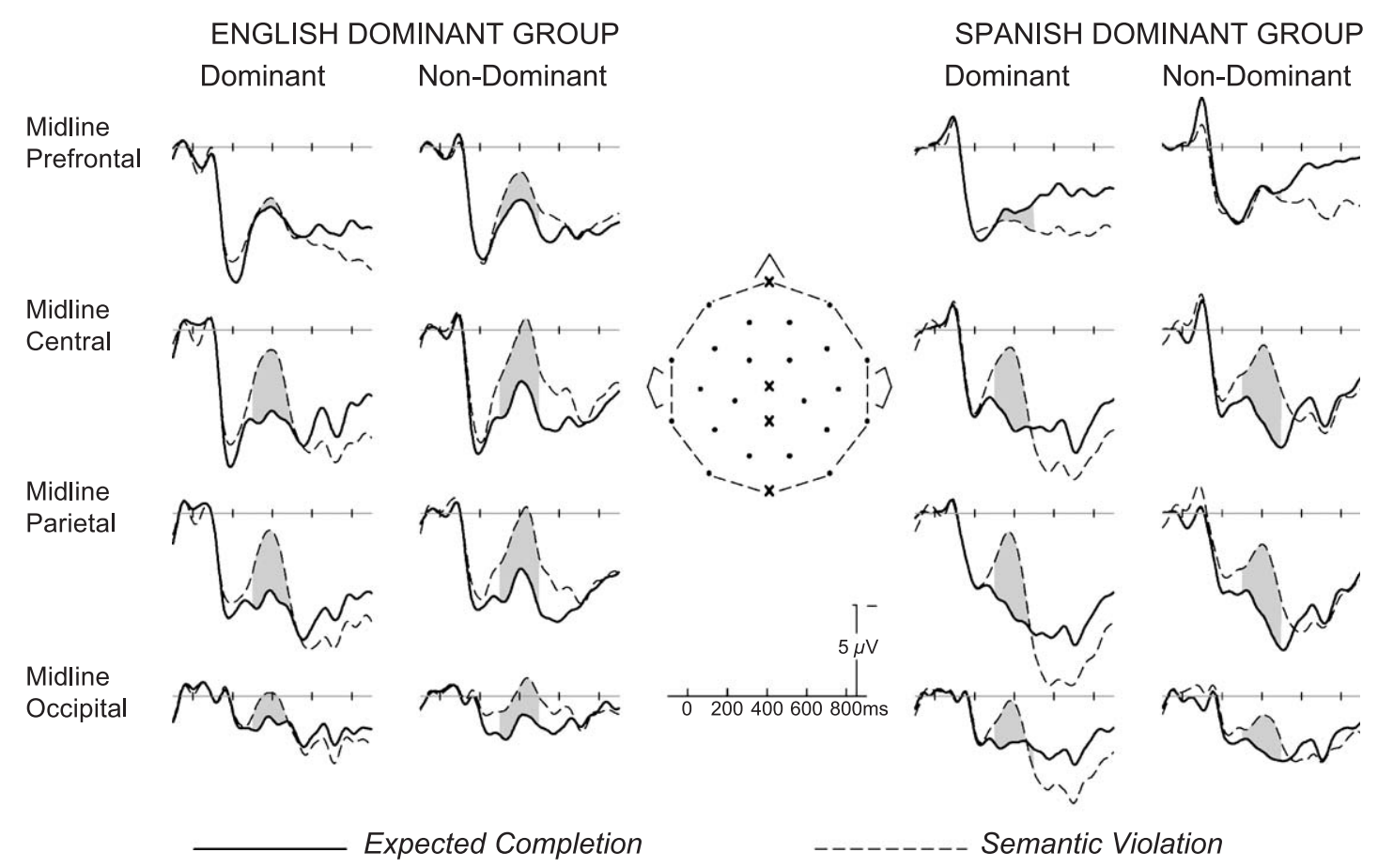

Fig. 2. N400 semantic congruity effect at midline sites as marked on small head icon (from top to bottom: Prefrontal, Central, Parietal, and Occipital) for English-dominant group on the left side of the figure and Spanish-dominant group on the right side of the figure. For each group, are plotted ERPs to expected (solid) versus anomalous (dashed) endings for their dominant language (left column) and their nondominant language (right column). Shaded areas represent the time window $(300-500 \mathrm{~ms})$ in which $\mathrm{N} 400$ measures were taken.

However, the latency of the N400 peak was significantly delayed for the nondominant relative to the dominant language. Moreover, the response to congruent endings appeared to be less positive in the nondominant language, especially over frontal sites. Semantic violations in the dominant language also elicited a larger late positive component (LPC) following the N400 than those in the nondominant language.

\subsection{N400 amplitude analyses}

Mean amplitude was measured in the $300-500 \mathrm{~ms}$ time window $^{1}$ relative to $100 \mathrm{~ms}$ prestimulus baseline and subjected to an omnibus analysis of variance (ANOVA) with one between-group factor: language group (English dominant vs. Spanish dominant) and five within-subject factors: language dominance (dominant vs. nondominant), sentence congruence (congruent vs. anomalous), hemisphere (left, right), laterality (lateral, medial) and anteriority (prefrontal, frontal, central and occipital). All $p$ values in this and all subsequent analysis are reported after Huynh-

\footnotetext{
${ }^{1}$ The N400 to semantic anomalies shifts its latency depending on the language of dominance and appears to last longer for the less-dominant language. However, the more-dominant language waveform also shows an LPC immediately following the N400. To avoid potential confounds with longer lasting or later effects, the narrower 300-500 window was selected to measure N400 amplitude across languages.
}

Felt epsilon correction for repeated measures with more than 1 degree of freedom.

There was no main effect of group nor any significant interaction of group with any of the other factors; overall, the N400 was equivalent in amplitude for the English- and Spanish-dominant groups for both their dominant and nondominant languages.

The analysis yielded a main effect of language dominance $[F(1,38)=4.59 ; p \mathrm{HF}=0.03]$ reflecting about half a microvolt more positivity for the dominant $(2.60 \mu \mathrm{V})$ relative to the nondominant language $(2.13 \mu \mathrm{V})$ in the N400 time window. This factor interacted marginally $(p \mathrm{HF}=0.09)$ with anteriority, indicating a tendency for this amplitude difference to decrease gradually from the prefrontal toward the occipital sites (Prefrontal, 3.09 vs. $2.33 \mu \mathrm{V}$; Frontal, 2.10 vs. $1.53 \mu \mathrm{V}$; Central, 2.25 vs. 1.84 $\mu \mathrm{V}$; Occipital, 2.94 vs. $2.83 \mu \mathrm{V}$, for Dominant and NonDominant Language, respectively).

As can be seen in Fig. 2, the ANOVA also indicated a robust main effect of semantic congruity $[F(1,38)=43.43$; $p \mathrm{HF}=0.0000]$ : semantic anomalies were about a microvolt and a half more negative $(1.56 \mu \mathrm{V})$ than semantically congruent endings $(3.17 \mu \mathrm{V})$. Semantic congruity did not interact with either group $[F(1,38)=0.01, p \mathrm{HF}=$ n.s. $]$ or language dominance $[F(1,38)=0.43, p \mathrm{HF}=$ n.s.]. The $\mathrm{N} 400$ congruity effect was bilaterally symmetric [congruity by hemisphere interaction $F(1,38)=1.35 ; p \mathrm{HF}=$ n.s.], was larger over medial $(2.17 \mu \mathrm{V})$ than lateral sites (1.05 $\mu \mathrm{V})[F(1,38)=31.07 ; p \mathrm{HF}=0.0000]$, and interacted with 
anteriority $[F(3,114)=7.62 ; p \mathrm{HF}=0.0079]$, reflecting its maximum at central sites $(2.04 \mu \mathrm{V})$, followed by frontal $(1.74 \mu \mathrm{V})$ and occipital sites $(1.69 \mu \mathrm{V})$, being smallest at prefrontal sites $(0.98 \mu \mathrm{V})$. This scalp distribution generally corresponds with that of the typical N400 semantic congruity effect.

We also measured the N400 effect in the difference ERP (incongruous ending minus congruous ending). Analyses of these showed no significant differences in amplitude or topography across the two participant groups or for the dominant versus nondominant language.

\subsection{Timing of the N400 congruity effects}

An ANOVA was performed on peak latency measures taken from the difference ERPs (congruity effect) lowpass filtered at $5 \mathrm{~Hz}$ to avoid spurious peak selection. The analysis included one between-subject factor (group) and two within-subject factors: language dominance (dominant vs. nondominant) and electrode (26 sites). The two groups did not differ from each other in the latency of N400 congruity effect overall $[F(1,38)=0.25, p=$ n.s. $]$ or in interaction with language dominance $[F(1,38)=0.33$; $p \mathrm{HF}=\mathrm{n} . \mathrm{s}]$. As can be seen in Fig. 3, however, the peak latency of the N400 effect was significantly earlier in the dominant $(390 \mathrm{~ms})$ than nondominant $(417 \mathrm{~ms})$ language $[F(1,38)=15.60 ; p \mathrm{HF}=0.0003]$. Pairwise comparisons revealed that this delay in peak latency of the N400 congruity effect in the nondominant language is reliable in both groups [English dominant: 394 vs. $417 \mathrm{~ms}$, $F(1,19)=4.68, p \mathrm{HF}=0.043$; Spanish dominant: 385 vs. $416 \mathrm{~ms}, F(1,19)=13.01 ; p \mathrm{HF}=0.0019 ;$ Fig. 4]. In the "balanced bilinguals" $(N=7)$, the peak latency of the N400 congruity effect did not differ across languages $[F(1,6)=1.26 ; p \mathrm{HF}=$ n.s. $]$. While not as robust as the peak latency measures, onset measures also revealed a marginal

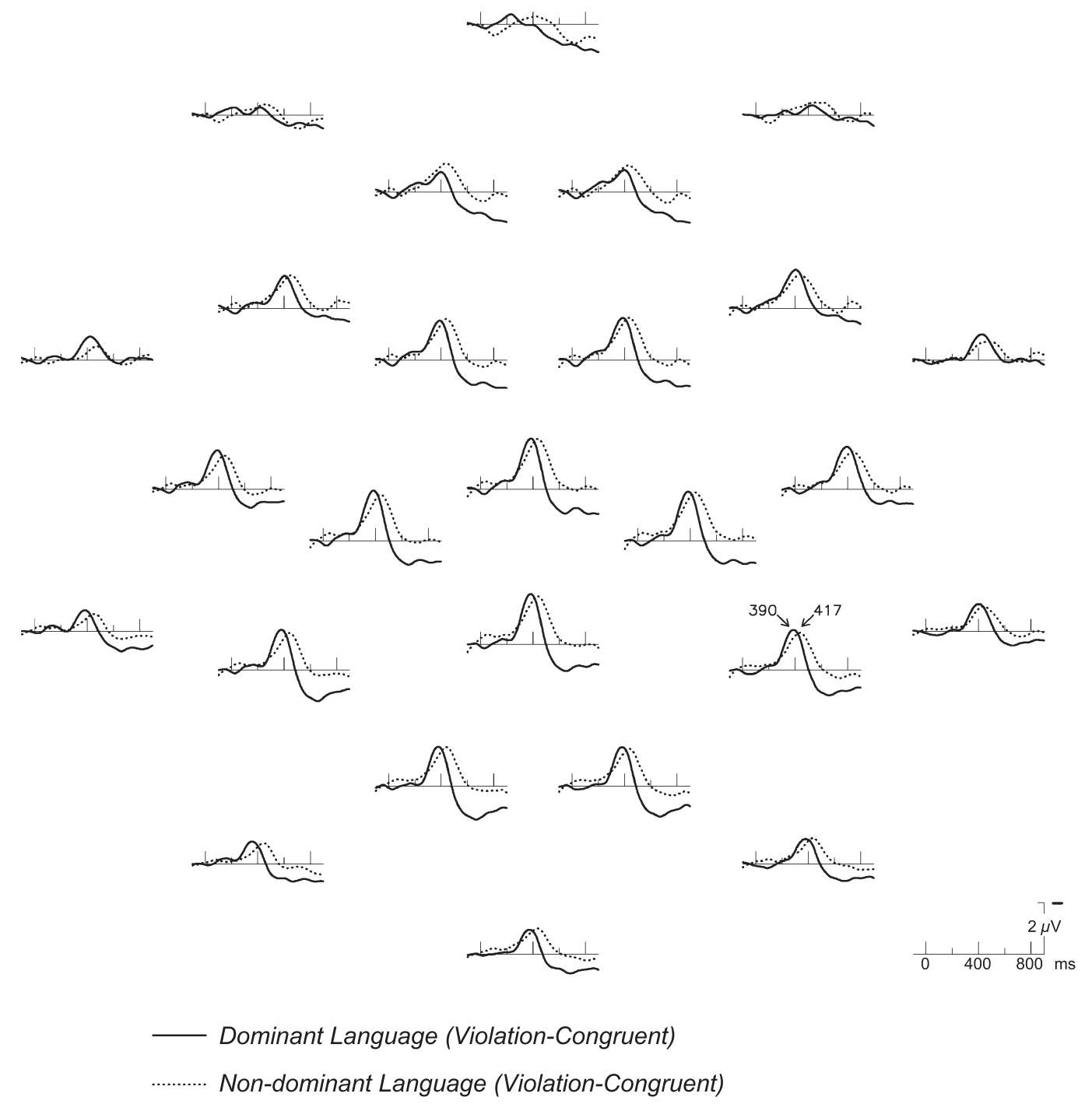

Fig. 3. N400 effect (semantic violation minus congruent ending ERPs) for dominant (solid) and nondominant (dotted) languages at 26 scalp sites. Arrows point to the peak latency of the N400 effect at a particular channel, although the written values $-390 \mathrm{~ms}$ for dominant and $417 \mathrm{~ms}$ for nondominant - are means across 26 channels. 


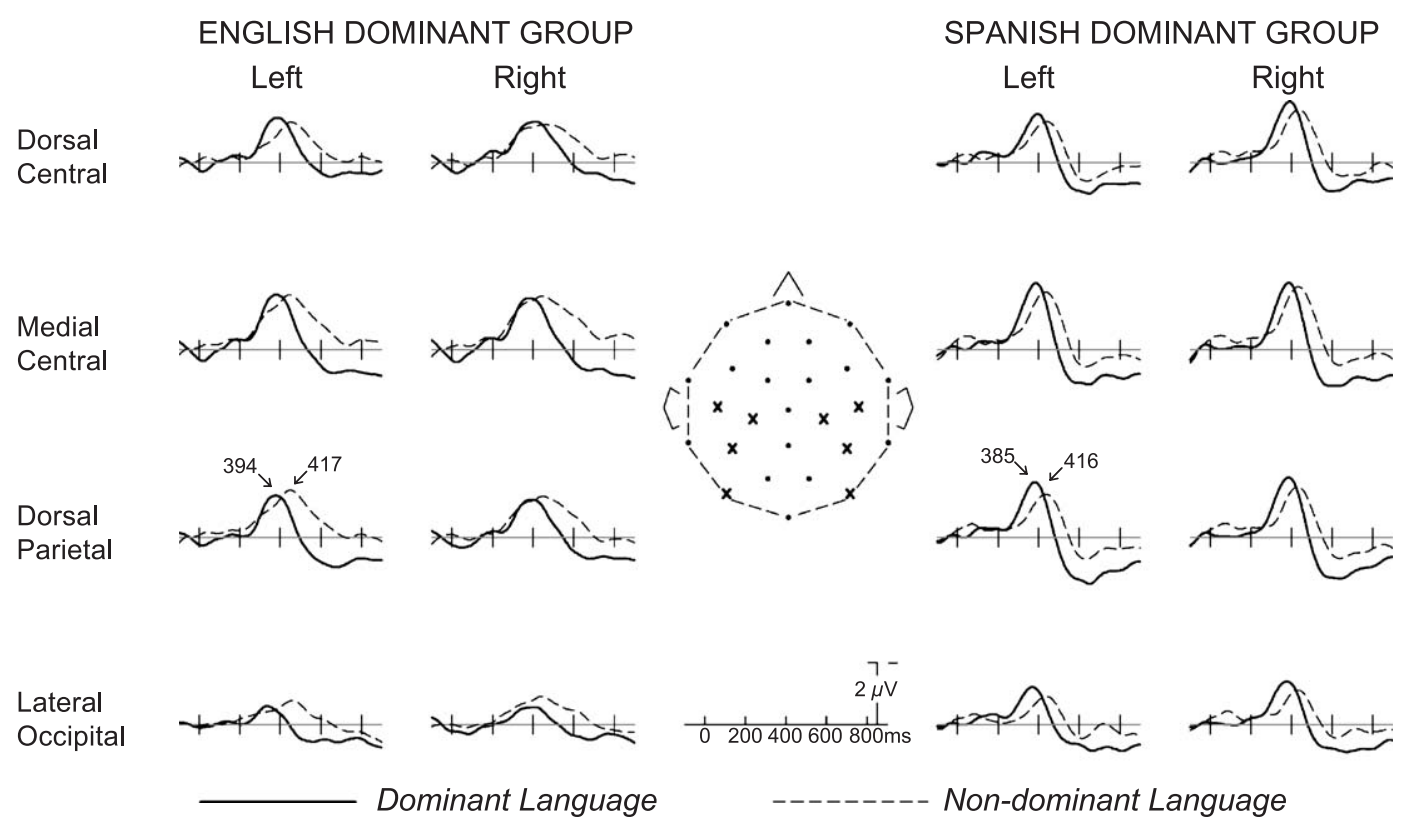

Fig. 4. The N400 effect at eight representative sites for both the English-dominant and Spanish-dominant bilingual subgroups.

difference, with the N400 congruity effect beginning $\sim 10$ $\mathrm{ms}$ earlier for the dominant versus nondominant language $[F(1,38)=3.48 ; p \mathrm{HF}=0.069]$.

\subsection{Regression analyses on the latency of the N400 effects}

Visual N400 congruity effects typically have a posterior distribution sometimes with a slight right bias. In our case, the N400 effect was posterior with the largest latency difference between the dominant and nondominant languages at Left Lateral Occipital (LLOc; 368 vs. 424 ms). Thus, peak latency measures for each participant were taken from LLOc to determine the degree to which N400 effect latency was correlated with age of language exposure, proficiency as reflected in the three vocabulary measures (BNT, letter fluency, category fluency), and age since the Spanish-dominant group was on average older than the English-dominant group.

We first performed correlation analyses, as traditionally reported in the literature on bilingualism, for the subset of our participants $(N=31)$ who were exposed to one language (L1) at birth (in this case Spanish) and to their second language (L2, in this case English) later in life (mean=8 years; S.D. $=5.5$ years). In agreement with the results of Weber-Fox and Neville, as can be seen in Table 3 and Fig. 5, the latency of the N400 effect in L2 was highly correlated with the age of exposure to $\mathrm{L}^{2} \quad(r=0.55, p=0.001)$.

\footnotetext{
2 These and all subsequent analyses were additionally performed on the averaged peak latency computed from three left parietal, temporal and occipital channels in order to examine the consistency of the correlations over a wider set of channels. Correlation values at the channel position for which differences in latency across languages was maximal (LLOc) will be explicitly reported in the text for brevity purposes. Please refer to Table 6 for the pattern of correlations across these three channels.
}

However, it was also inversely correlated with various measures of vocabulary proficiency (BNT: $r=-0.54$, $p=.001$; category fluency: $r=-0.39, p=0.01)$ and positively correlated with age $(r=0.55, p=0.001)$.

A multiple sequential regression analysis performed on these latency measures in L2 at LLOc indicated that age of exposure and BNT proficiency each account for some of the variance in N400 latency response even when the contribution of the other factor has been taken into account: once BNT has been accounted for, age of exposure accounts for an additional $0.16 R^{2}(p=.008)$ in N400 latency and likewise BNT accounts for an additional $14 \%$ of the variance in N400 latency variance once age of exposure has been accounted for $(p=0.01)$. Both LLOc and multiposterior channel analyses show that the most predictive power for N400 peak latency in L2 (English) appears to be shared between the two predictors, which are themselves inversely correlated ( $r=-0.33, p=0.03)$, as in most investigations of bilinguals.

Analyses of the peak latency of the N400 congruity effect for the native language (L1), for which age of exposure to the language was fixed, also revealed significant inverse correlations with each of the vocabulary measures (BNT: $r=-0.51, p=0.002$; category fluency: $r=-0.41, p=0.01$; letter fluency: $r=-0.53, p=0.001$ ). There was also a counterintuitive inverse correlation with age, with older participants having shorter N400 latencies ( $r=-0.28, p=0.06$ ); however, this is probably because most of the participants in this subset of 31 were Spanishdominant bilinguals who as stated previously were on average older (but more proficient in L1) than the Englishdominant bilinguals.

We also examined the correlation between age of exposure, vocabulary proficiency, and age on N400 peak 
Table 3

Means and standard deviations on various characteristics of our bilingual participants split according to language dominance (greater than 20 point difference on BNT in the two languages)

\begin{tabular}{|c|c|c|c|c|c|c|}
\hline \multirow[t]{3}{*}{ Age (years) } & \multicolumn{3}{|c|}{ Spanish-dominant group } & \multicolumn{3}{|c|}{ English-dominant group } \\
\hline & \multicolumn{3}{|l|}{$30(4)$} & \multicolumn{3}{|l|}{$23(3)$} \\
\hline & $\begin{array}{l}\text { Dominant } \\
\text { language } \\
\text { (Spanish) }\end{array}$ & $\begin{array}{l}\text { Nondominant } \\
\text { language } \\
\text { (English) }\end{array}$ & Difference & $\begin{array}{l}\text { Dominant } \\
\text { language } \\
\text { (English) }\end{array}$ & $\begin{array}{l}\text { Nondominant } \\
\text { language } \\
\text { (Spanish) }\end{array}$ & Difference \\
\hline $\begin{array}{l}\text { Self-reported language } \\
\text { proficiency }(1-7)\end{array}$ & $7(0)$ & $5(1)$ & & $7(1)$ & $5(1)$ & \\
\hline Age of exposure (years) & $0(1)$ & $10(6)$ & & $2.6(2.4)$ & $1(3)$ & \\
\hline Language use (\%) & 80 & 11 & & 55 & 44 & \\
\hline Boston Naming Test (1-60) & $58(2)$ & $36(7)$ & $21(6)$ & $51(6)$ & $29(8)$ & $22(10)$ \\
\hline Letter Verbal Fluency Test & $59(8)$ & $37(8)$ & $22(9)$ & $43(10)$ & $36(9)$ & 7 (11) \\
\hline Category Verbal Fluency Test & $51(8)$ & $34(8)$ & $16(7)$ & $40(7)$ & $27(9)$ & $13(9)$ \\
\hline
\end{tabular}

latency (at LLOc) for the dominant and the nondominant language, whether they were English or Spanish. For the nondominant language, N400 latency was negatively correlated with category fluency; better category fluency score was associated with earlier peak latency $(r=-0.34$, $p=0.01$ ). For the dominant language, peak latency was marginally correlated with age, older adults showing longer latency N400 congruity effects $(r=0.27, p=0.05)$.
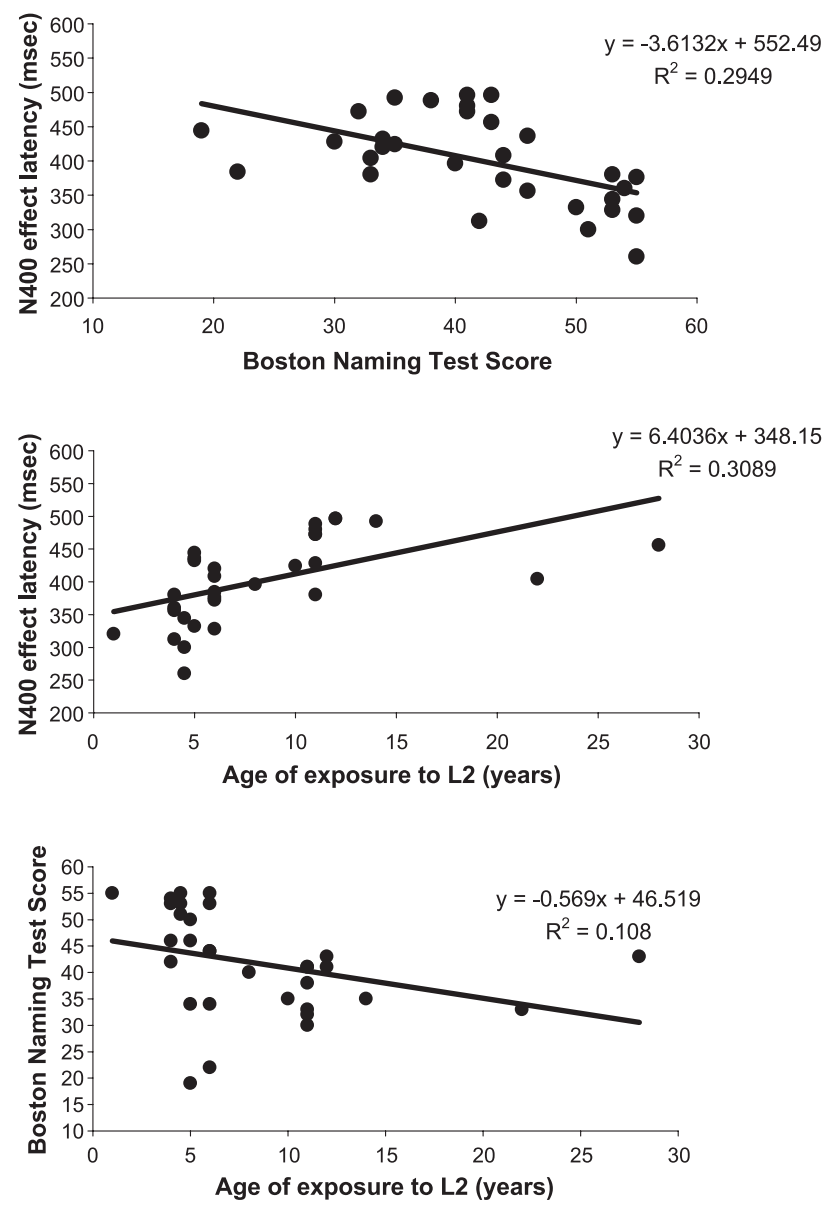

Fig. 5. Correlation of N400 effect latency with BNT score in L2 (top) and age of exposure to L2 (middle), and correlation between BNT score and age of exposure to L2 (bottom).
It also showed a counterintuitive correlation with vocabulary proficiency, with longer N400 latencies associated with greater proficiency (BNT: $r=0.29, p=0.03$; letter fluency: $r=0.33, p=0.02$ ), which we believe is due to an age confound. Overall, BNT and letter fluency scores were correlated with age, being higher for the older participants $(r=0.63, p=0.000$; and $r=0.56, p=0.000$, respectively). And, since N400 latency was overall later for the older participants, slower N400s were associated with better BNT and letter fluency scores; this was primarily due to the Spanish dominants who were generally older and had higher BNT and letter fluency scores in their dominant language than did English dominants (refer to Table 4).

Correlation analyses were conducted for each dominance group for each language separately (see Table 5 and Fig. 6). For the dominant language, no significant correlations were obtained between N400 latency and any measure for either group. However, despite the reduced sample size $(N=20)$, the pattern of correlations for the nondominant language did differ between the groups. For the English-dominant group, N400 latency in the nondominant language (Spanish) was significantly correlated with all the vocabulary measures (BNT: $r=-0.45, p=0.02$; letter fluency: $r=-0.45, p=0.02$; category fluency: $r=-0.47, p=0.01$ ) and not with age of exposure. In contrast, for the Spanish-dominant group, N400 latency for the nondominant language (English) was significantly correlated with age of exposure ( $r=$ $-0.42, p=0.03$ ) and not with any of the vocabulary measures.

Finally, analysis of the English dominants in their nondominant but sometimes native language (Spanish; Table 5) indicated that although they too show an association between age of exposure and vocabulary proficiency, with later age of exposure associated with worse proficiency (BNT: $r=-0.34, p=0.07$; letter fluency: $r=-0.43, p=0.03$; and category fluency: $r=-0.34$, $p=0.07$ ), in this case, N400 peak latency is significantly correlated only with vocabulary measures and not with age of exposure. 
Table 4

Significant Pearson (one-tailed) correlations and multiple sequential regression analyses of N400 peak latency in L1 and L2 with vocabulary proficiency measures, age of exposure, and age

\begin{tabular}{|c|c|c|c|c|c|c|c|c|}
\hline & & & & Boston naming & $\begin{array}{l}\text { Letter } \\
\text { fluency }\end{array}$ & $\begin{array}{l}\text { Category } \\
\text { fluency }\end{array}$ & $\begin{array}{l}\text { Age of } \\
\text { exposure }\end{array}$ & Age \\
\hline \multirow{6}{*}{$\begin{array}{l}\text { Participants exposed } \\
\text { to Spanish at birth } \\
\text { and to English } \\
\text { later in life }(N=31)\end{array}$} & \multirow[t]{4}{*}{ L2 (English) } & LLOc & $\begin{array}{l}\text { Pearson sig. } \\
\text { (one-tailed) }\end{array}$ & $-0.54,0.001$ & & $-0.39,0.01$ & $0.55,0.001$ & $0.55,0.001$ \\
\hline & & $\begin{array}{l}\text { Avg. } \\
\text { chans }\end{array}$ & $\begin{array}{l}\text { Pearson sig. } \\
\text { (one-tailed) }\end{array}$ & $-0.27,0.07$ & & $-0.26,0.08$ & $0.43,0.008$ & $0.44,0.007$ \\
\hline & & LLOc & $\begin{array}{l}R^{2} \text { change } \\
\text { sig. } F \text {. change }\end{array}$ & 0.14 (AOE), 0.01 & & & $\begin{array}{l}0.16(\mathrm{BNT}) \\
0.008,0.20 \\
\text { (CAT) } 0.006\end{array}$ & \\
\hline & & $\begin{array}{l}\text { Avg. } \\
\text { chans }\end{array}$ & $\begin{array}{l}R^{2} \text { change } \\
\text { sig. } F \text {. change }\end{array}$ & & & & $\begin{array}{l}0.13 \text { (BNT), } 0.04 \\
13 \text { (CAT), } 0.04\end{array}$ & \\
\hline & \multirow[t]{2}{*}{ L1 (Spanish) } & LLOc & $\begin{array}{l}\text { Pearson sig. } \\
\text { (one-tailed) }\end{array}$ & $-0.51,0.002$ & $-0.41,0.01$ & $-0.53,0.001$ & & $-0.28,0.06$ \\
\hline & & $\begin{array}{l}\text { Avg. } \\
\text { chans }\end{array}$ & $\begin{array}{l}\text { Pearson sig. } \\
\text { (one-tailed) }\end{array}$ & $-0.50,0.002$ & $-0.37,0.02$ & $-0.47,0.007$ & & \\
\hline
\end{tabular}

Results are shown separately for each language. Analysis at LLOc as well as for the combined average of three posterior (parietal, temporal and occipital) channels (Avg. chans). In parentheses in the two most inferior rows indicate what factor had been accounted for before $R^{2}$ change is estimated for the relevant factor in that column.

\subsection{Late differences in the processing of dominant and nondominant languages}

Following the N400 was a late positive component (LPC). Its amplitude was measured between 600 and 900 $\mathrm{ms}$ to avoid overlap with the slightly longer lasting N400 for the nondominant language. There were no significant group differences in LPC amplitude, but there was a main effect of language dominance $[F(1,38)=27.4, p \mathrm{HF}=0.00]$, with greater positivity for the dominant $(3.95 \mu \mathrm{V})$ than nondominant language $(2.88 \mu \mathrm{V})$. Likewise, there was a reliable effect of congruity on the LPC $[F(1,38)=10.72$, $p \mathrm{HF}=0.002]$, with greater positivity to incongruent $(3.80$ $\mu \mathrm{V})$ than congruent endings $(3.03 \mu \mathrm{V})$. Unlike the $\mathrm{N} 400$, however, language dominance and congruity interacted $[F(1,38)=8.78, p \mathrm{HF}=0.005]$, which pairwise comparisons indicated was due to a significant congruity effect across the scalp only in the dominant language [congruent: $3.26 \mu \mathrm{V}$ vs. incongruent: $4.65 \mu \mathrm{V} ; F(1,39)=42.39 ; p \mathrm{HF}=0.00]$ and not in the nondominant language $(2.80$ vs. $2.95 \mu \mathrm{V})$, which showed a more focal congruity effect [congruity by electrode, $F(25,975)=3.83 ; p \mathrm{HF}=0.0053]$; larger at midline central and parietal electrode sites.

\subsection{Language dominance effect}

Language dominance appeared to have an effect throughout the recording epoch (Fig. 7); this was assessed statistically via an ANOVA including three within-subject factors: six $100 \mathrm{~ms}$ time windows from 300 to $900 \mathrm{~ms}$, two levels of language dominance, 26 scalp channels, and one between-subjects factor: 40 subjects. A main effect of time window $[F(5,195)=14.13 ; p \mathrm{HF}=0.0000]$ indicated that the ERP was most positive between 500 and $600 \mathrm{~ms}$. Words in the dominant language generally elicited a larger positivity $(3.65 \mu \mathrm{V})$ than those in the less-dominant language $(2.76$ $\mu \mathrm{V})[F(1,39)=19.66 ; p \mathrm{HF}=0.0001]$ at all recording sites with the exception of the 300-400 ms interval in which language dominance interacted with electrode site [language dominance by time window, $F(5,195)=6.76 ; p \mathrm{HF}=0.00]$; planned comparisons are shown in Table 6 . Further analysis with a restricted set of electrode sites revealed a marginal interaction of language dominance with hemisphere and anteriority $[F(1,39)=4.02 ; p \mathrm{HF}=0.05$, and $F(3,117)=3.12$, $p \mathrm{HF}=0.08$, respectively], indicating a tendency for the language dominance effect between 300 and $400 \mathrm{~ms}$ to be larger over left prefrontal sites (see topographic map in Fig. 8).

\subsection{Summary}

In summary, whether reading sentences word by word in their dominant or nondominant language, be it L1 or L2, all participants responded to semantic anomalies with a larger N400 (300-500 ms) relative to semantically congruent endings. Consistent with previous reports, the

Table 5

Significant Pearson (one-tailed) correlations of N400 peak latency in dominant and nondominant languages for each group with various vocabulary proficiency measures, age of exposure to the language, and chronological age

\begin{tabular}{llllll}
\hline & & Boston naming & Letter fluency & Category fluency & Age of exposure \\
\hline Spanish dominants $(N=20)$ & $\begin{array}{l}\text { Dominant (Spanish) } \\
\text { English dominants }(N=20)\end{array}$ & & & $.42, .03$ \\
& $\begin{array}{l}\text { Nondominant (English) } \\
\text { Dominant (English) } \\
\text { Nondominant (Spanish) }\end{array}$ & $-0.45,0.02$ & $-0.45,0.02$ & $-0.47,0.01$ & \\
\hline
\end{tabular}


English Dominants in Non-dominant (Spanish)

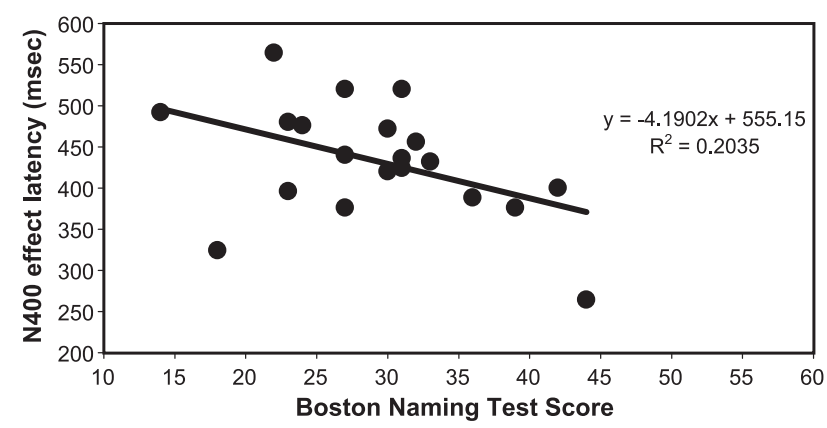

Spanish Dominants in Non-dominant (English)

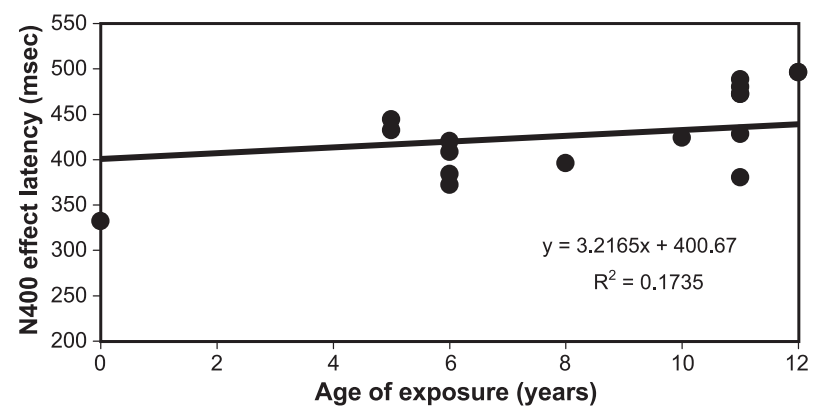

Fig. 6. Correlation of N400 effect latency in nondominant language with (a) BNT score for English-dominants in Spanish (top), and (b) age of exposure to nondominant language for Spanish-dominants in English (bottom).

N400 congruity effect in bilinguals was delayed $(\sim 10 \mathrm{~ms}$ in onset and $\sim 27 \mathrm{~ms}$ at their peak) for the nondominant relative to the dominant language. This delay was evident regardless of which language was dominant and despite the bilinguals' differing language histories. Correlation analyses within the participants who were exposed to Spanish at birth and to English later in life $(N=31)$, revealed that (1) age of exposure and vocabulary proficiency (as measured by BNT and category fluency) were correlated with each other, (2) both reliably correlated with the latency of the N400 congruity effect latency for L2 (English) to about the same degree, and (3) each factor accounted for a small, albeit significant, amount of the variance in N400 latency after the contribution of the other factor had been partialled out. Moreover, the latency of N400 congruity effect in L1 was significantly correlated with all vocabulary proficiency measures (BNT, letter and category fluency) when age of exposure to L1 (Spanish) was held constant. Finally, collapsed across congruity, ERPs were more positive to endings in the dominant than nondominant language.

\section{Discussion}

The relative importance of age of exposure and language (specifically vocabulary) proficiency on the speed of semantic analysis in both languages of Spanish-English bilinguals was explored via electrophysiological recordings taken during word-by-word sentence reading. Specifically, ERPs were recorded to sentence final words in bilinguals reading sets of isolated sentences for meaning-separate blocks in English and in Spanish; in each block, a random half of the sentences ended sensibly whereas the other half ended with a semantically anomalous word. Not surprisingly, the onset and peak latencies of the N400 effect (ERPs to anomalous minus congruent endings) — an effect linked to semantic analysis - were delayed for the language in which bilinguals were less proficient (based on Boston Naming Test scores) $[3,28,52]$. At issue, however, is the extent to which this relative delay reflects differences in age of exposure to each language, current proficiency with it, or some combination thereof. In prior electrophysiological studies with bilinguals, these two factors often were so highly correlated that it was neigh impossible to tease apart their individual contributions. This is also the case in the current study in those bilinguals for whom Spanish is the native and dominant language and English is the later learned, nondominant one. However, for a subset of our bilingual participants - for whom English is currently the dominant language - it is possible to, at least partially, decouple these two factors as they had been exposed to both Spanish and English relatively early (Spanish often earlier) and continue to use both daily, but nonetheless were more proficient in English than Spanish at the time of testing.

To the extent that early, informal acquisition of a first language buffers the lexical and semantic processes of that language system from degradation and/or from the processing costs of between language competition [31], we would have expected to observe no significant differences between the N400 effects in the two languages of this subgroup of bilinguals dominant in English. However, this was not the case. Like the Spanish-dominant subgroup, the Englishdominant subgroup exhibited significantly delayed N400 effects in their less (vs. more) proficient language. That is, they had longer latency N400 effects to semantic incongruities in their nondominant language (Spanish) relative to their dominant language (English). Age of acquisition alone thus cannot be the sole determinant of how quickly a word is recognized and integrated into a sentence context at a semantic level. Proficiency with the vocabulary of a language clearly also plays a critical role, for even when age of exposure is comparatively early for both languages, in some cases even earlier for the nondominant language, the N400 effect still is delayed in the nondominant compared to the dominant language. These essentially "native" Spanishspeaking bilinguals were less proficient in Spanish than English and in turn slower to appreciate that a Spanish word did not fit in a sentence context, although they had no obvious trouble understanding these sentences. Although Spanish was their nondominant language, it was one that they continued to use on a daily basis with family and/or friends, although perhaps not as intensively as English. As mentioned in the Introduction, vocabulary knowledge seems to be especially vulnerable to loss with decreased use and 
DOMINANT AND NON-DOMINANT LANGUAGE ERPS

(COLLAPSED ACROSS DOMINANCE \& SENTENCE CONGRUITY)

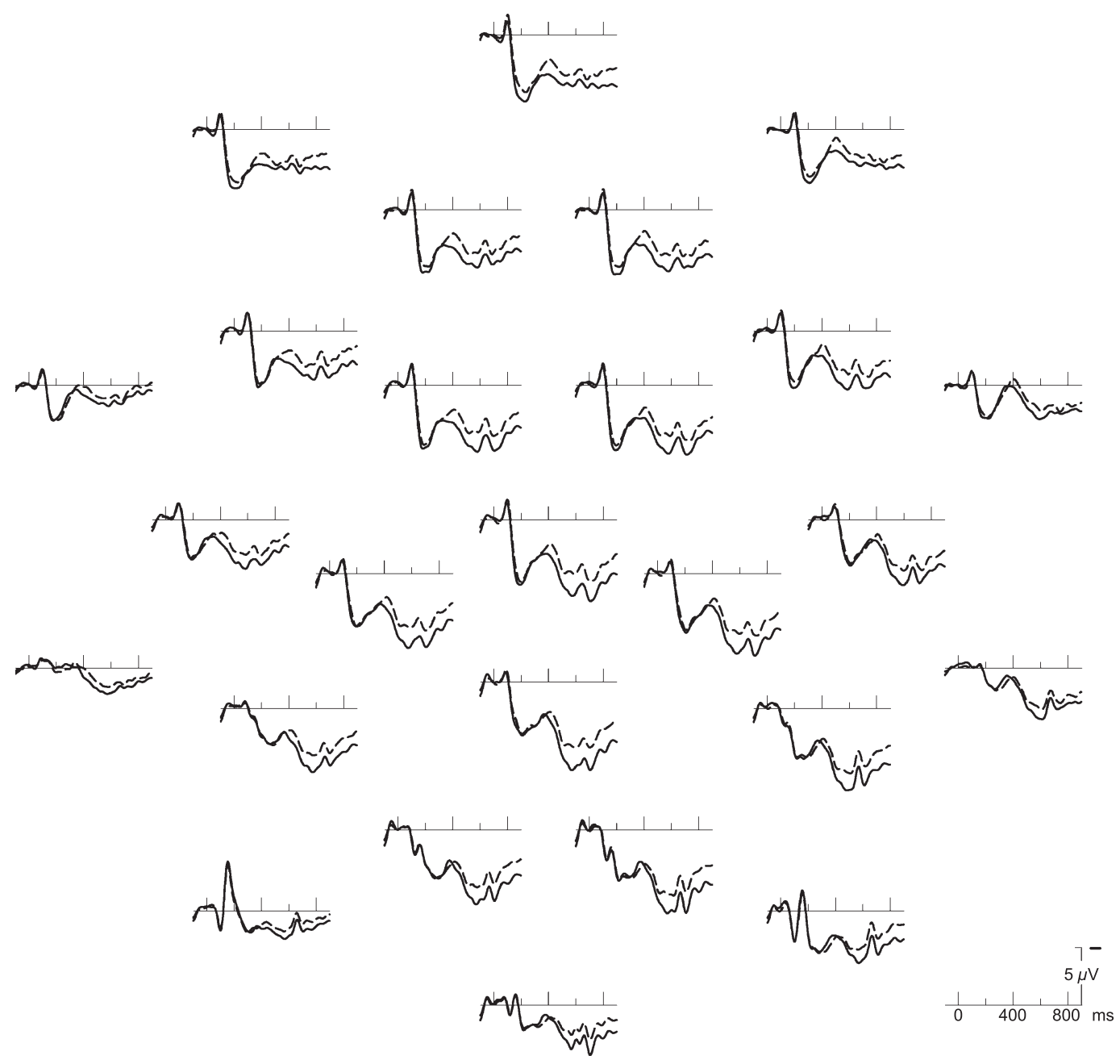

- Dominant Language

---- Non-dominant Language

Fig. 7. Language of dominance effect. Average ERPs to dominant (solid) versus nondominant (dashed) languages over 26 scalp channels for all bilinguals.

our results indicate that the timing of the N400 congruity effect is sensitive to this change. In summary, both age of acquisition and vocabulary proficiency make contributions to the speed with which words are integrated into a semantic context during sentence reading.
In our study, the extent to which language proficiency (as indexed by vocabulary and fluency scores) and age of exposure were predictive of the speed of semantic processing (as indexed by N400) differed as a function of the bilingual's group language history and the language under

Table 6

Planned comparisons for the language of dominance effect across six $100 \mathrm{~ms}$ time windows from 300 to $900 \mathrm{~ms}$

\begin{tabular}{|c|c|c|c|c|c|c|c|}
\hline Time (ms) & & $300-400$ & $400-500$ & $500-600$ & $600-700$ & $700-800$ & $800-900$ \\
\hline \multirow{4}{*}{$\begin{array}{l}\text { Language of } \\
\text { dominance in } \mu \mathrm{V}\end{array}$} & Dominant & 2.35 & 3.06 & 4.59 & 4.26 & 4.18 & 3.44 \\
\hline & Nondominant & 2.24 & 2.21 & 3.50 & 3.18 & 3.11 & 2.34 \\
\hline & $F(1,39)$ & 0.20 & 12.01 & 16.05 & 20.0 & 23.19 & 22.23 \\
\hline & $p \mathrm{HF}$ & n.s. & 0.001 & 0.0003 & 0.0001 & 0.0000 & 0.0000 \\
\hline \multirow{2}{*}{$\begin{array}{l}\text { Language of } \\
\text { dominance by electrode }\end{array}$} & $F(25,975)$ & 2.48 & 1.85 & 2.05 & 2.0 & 2.17 & 2.31 \\
\hline & $p \mathrm{HF}$ & 0.05 & n.s. & n.s. & n.s. & 0.08 & 0.05 \\
\hline
\end{tabular}



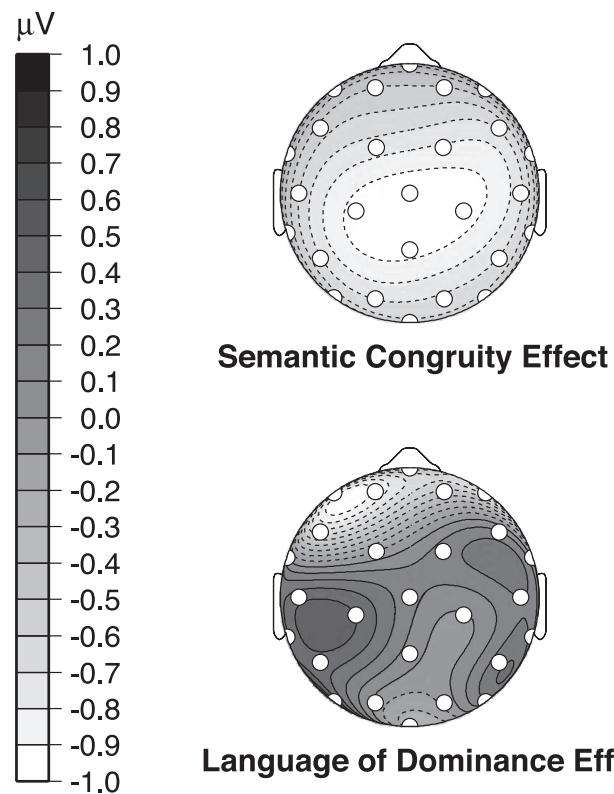

Language of Dominance Effect

Fig. 8. Scalp distribution of N400 semantic congruity and language of dominance effects between 300 and $400 \mathrm{~ms}$. The scalp distribution of the negativity shows a centro-parietal focus for the N400 semantic congruity effect (top) and a left anterior focus for the language of dominance effect (bottom).

question. For instance, in the nondominant language, N400 latency was predicted by vocabulary proficiency in the English-dominant subgroup and by age of exposure in the Spanish-dominant subgroup (see Fig. 6). In line with previous results, both age of exposure $(r=0.55)$ and vocabulary scores $(r=0.54)$ correlated reliably with the speed of semantic processing in L2 (English), as well as inversely with each other $(r=-0.33)$. By contrast, speed of semantic integration in L1 was well correlated with vocabulary proficiency $(r=0.41-0.53)$, although it was not highly correlated with age of exposure (all early), suggesting that the two factors can make independent contributions. And, in fact, both these factors explained a small, but significant amount of the variance in the latency of the N400 congruity effect, when the other factor was partialled out, even in L2.

In contrast to the N400 latency differences, we found no reliable differences in the sizes of the N400 congruity effects across languages. Apparently, these bilinguals devoted approximately equivalent processing resources to the task of appreciating the relation between each sentence final word and the semantic representation of the sentence context up to that point. We did, however, find that the ERPs to sentence final words (collapsed across congruity) in the dominant language were more positive from 300 to 900 $\mathrm{ms}$. Between 300 and $400 \mathrm{~ms}$, this language dominance effect (greater negativity or less positivity to the nondominant language) had a left frontal focus. This topographical difference in the ERPs elicited by final words in the two languages of a bilingual superficially resembles a left anterior negativity (LAN) effect. LAN effects have been associated to syntactic processes, such as phrase structure violations within sentences [11,34,35], or more generally with working memory processes $[18,20,45]$. If this effect is a LAN, then it might reflect greater working memory demands when bilinguals process their nondominant language versus their dominant language.

Alternatively, this effect also resembles ERP word concreteness effects: greater negativity frontally for concrete than abstract words between 300 and $500 \mathrm{~ms}[23,39,54]$. Imageability/concreteness ERP effects have been reported to have a frontal focus [47]. This superficial similarity leads to the intriguing, though admittedly highly speculative, hypothesis that bilinguals may adopt a relatively more "concrete/literal" than "abstract/metaphorical" mode of processing when encountering written or aural materials in their weaker language. Although not yet directly tested, what little is known about concreteness effects in bilinguals is consistent with this hypothesis. In general, bilingual speakers/readers, like monolinguals, show concreteness effects (more accurate or faster performance with concrete than abstract words) across a range of tasks, including word association, priming, free recall, lexical decision and bilingual translation, among others $[38,48,49]$. Moreover, cross language priming is reportedly greater for concrete than abstract word pairs [15]. In addition, the overlap in associates given in response to single words in both L1 and L2 is greater when the eliciting word refers to a manipulable, concrete object than when it refers to an abstract state or emotion $[22,48]$. Finally, the ubiquitous concreteness effect for recall is more pronounced for the weaker language of unbalanced bilinguals [32]. If, indeed, abstract word meanings are generally less consistent and more context dependent, and therefore more language-specific than concrete words, then perhaps bilinguals may be slightly biased toward a more "concrete" interpretation of linguistic input in their weaker language whether the words per se would be rated as concrete or abstract. In other words, perhaps information retrieved from semantic memory to make sense of linguistic input tends to include relatively more concrete, imageable features during reading of the nondominant (than dominant) language.

We also examined the scalp distributions of the N400 congruity effects to see if there are any reliable differences in the functional brain organization for language in the bilingual relative to the monolingual brain and for $\mathrm{L} 1$ versus L2 in the bilingual brain. The typical visual N400 congruity effect in young adults has a posterior focus and a slight right greater than left asymmetry, although this is not always the case even on average, much less on an individual by individual basis $[29,50]$. Although there is a tendency for bilinguals to show a different hemispheric pattern than monolinguals, data on this are mixed with some researchers finding no hemispheric differences in N400 amplitudes (Weber-Fox and Neville [52] at least for bilinguals exposed to the language after the age of 3 ) and others finding a slight left-lateralized N400 asymmetry [3,4,43]. This inconsis- 
tency is characteristic of the literature on language laterality in bilinguals in general $[40,41]$.

In our study, we observed no significant asymmetry in the N400 effect in either language irrespective of whether the language was the dominant or nondominant one. Whether this reflects greater right hemisphere participation in the processing of both languages in these bilinguals is not something we can infer from these scalp-recorded potentials alone without further constraints due to the inverse problem (e.g., Ref. [51]). The absence of a laterality difference between the two languages in either group of bilinguals, however, is inconsistent with the modified stage hypothesis [30], which states that bilinguals initially rely more on the right hemisphere but with increasing second language proficiency engage primarily the left hemisphere.

Finally, our study reveals differences in the sentence congruity effect in the post-N400 region between 600 and $900 \mathrm{~ms}$, being broadly distributed for the dominant language and more localized over centro-posterior sites for the nondominant language. Late positivities in this time window are often linked to memory updating, encoding, and/or retrieval, given their appearance in tasks making demands on stimulus evaluation and memory updating resources $[7,9,29]$.

In conclusion, the timing of the electrophysiological response to the effect of semantic incongruity indicates faster appreciation/processing by a bilingual in their dominant language-i.e., that in which they display greater vocabulary proficiency. This is the case, even for those English-Spanish bilinguals who not only use both languages on a daily basis but also acquired both of them early in life. Our results suggest some presumably independent contributions of both age of exposure and language proficiency to the speed of semantic analysis/ integration. Whether exactly the same neural sources generate these congruity effects as those observed in monolinguals remains an open question. We also observed a post-N400 congruity effect that is more widespread for the dominant versus nondominant language, which we hypothesize, may be related to nonidentical memoryrelated processes for the two languages of nonbalanced bilinguals. Finally, we observed a slight tendency for a frontal negativity to be larger during nondominant language than dominant language processing; we speculate that bilinguals might adopt a relatively more concrete mode of processing for their nondominant as opposed to dominant language.

\section{Acknowledgements}

This work was supported by grants HD22614 and AG08313 to M.K. We thank K.D. Fedemeier, N.Y. Wicha, and J. Staab for their critical reading and very helpful comments to earlier versions of this manuscript.

\section{References}

[1] J. Abutalebi, S.F. Cappa, D. Perani, The bilingual brain as revealed by functional neuroimaging, Biling. Lang. Cogn. 4 (2001) 179-190.

[2] J.R. Alameda, F. Cuetos, Diccionario de las unidades Lingüísticas del Castellano, Servicio de Publicaciones de la Universidad de Oviedo, Oviedo, Spain, 1995.

[3] S. Ardal, M.W. Donald, R. Meuter, S. Muldrew, M. Luce, Brain responses to semantic incongruity in bilinguals, Brain Lang. 39 (1990) $187-205$.

[4] F. Barceló, M.E. de la Peña, C. Ayuso, J.A. Portellano, F.J. Rubia, Contribution of event-related potentials to hemispheric dominance in bilingual speakers, Rev. Psicol. Gen. Apl. 51 (1998) 5-15.

[5] A.L. Benton, K. Hamsher, Multilingual Aphasia Examination. Manual of Instructions, AJA Associates, Iowa City, 1978.

[6] D. Birdsong, M. Molis, On the evidence for maturational constraints in second-language acquisition, J. Mem. Lang. 44 (2001) 235-249.

[7] K.A. Brookhuis, G. Mulder, J.L. Mulder, A.B. Gloerich, H.J. van Dellen, J.J. van der Meere, H. Ellermann, Late positive components and stimulus evaluation time, Biol. Psychol. 13 (1981) 107-123.

[8] A.M. Dale, Source localization and spatial discriminant analysis of event-related potentials: linear approaches. Unpublished doctoral dissertation, University of California, San Diego, 1994.

[9] E. Donchin, M.G. Coles, Is the P300 component a manifestation of context updating? Behav. Brain Sci. 11 (1988) 357-427.

[10] W.N. Francis, H. Kucera, Frequency Analysis of English Usage, Houghton Mifflin, Boston, 1982.

[11] A.D. Friederici, E. Pfeifer, A. Hahne, Event-related potentials during natural speech processing: effects of semantic, morphological, and syntactic violations, Cogn. Brain Res. 1 (1993) 183-192.

[12] T.H. Gollan, R.I. Montoya, G.A. Werner, Semantic and letter fluency in Spanish-English bilinguals, Neuropsychology 16 (2002) 562-576.

[13] A. Hahne, What's different in second-language processing? Evidence from event-related brain potentials, J. Psycholinguist. Res. 30 (2001) $251-266$.

[14] A. Hahne, A.D. Friederici, Processing a second language: late learners' comprehension mechanisms as revealed by event-related brain potentials, Biling. Lang. Cogn. 4 (2001) 123-141.

[15] Y.-S. Jin, Effects of concreteness on cross-language priming in lexical decisions, Percept. Mot. Skills 70 (1990) 1139-1154.

[16] J. Johnson, E. Newport, Critical period effects in second language learning: the influence of maturational state on the acquisition of English as a second language, Cogn. Psychol. 21 (1989) 60-99.

[17] E. Kaplan, H. Goodglass, S. Weintraub, Boston Naming Test, Lea \& Febiger, Philadelphia, 1983.

[18] J.W. King, M. Kutas, Who did what and when? Using word- and clause-level ERPs to monitor working memory usage in reading, J. Cogn. Neurosci. 7 (1995) 376-395.

[19] K.H.S. Kim, N.R. Relkin, K.M. Lee, J. Hirsch, Distinct cortical areas associated with native and second languages, Nature 388 (1997) $171-174$

[20] R. Kluender, M. Kutas, Bridging the gap: evidence from ERPs on the processing of unbounded dependencies, J. Cogn. Neurosci. 5 (1993) $196-214$

[21] K.J. Kohnert, A.E. Hernandez, E. Bates, Bilingual performance on the Boston Naming Test: preliminary norms in Spanish and English, Brain Lang. 65 (1998) 422-440.

[22] P.A. Kolers, Interlingual word associations, J. Verbal Learn. Verbal Behav. 2 (1963) 291-300.

[23] J. Kounios, P.J. Holcomb, Concreteness effects in semantic processing: ERP evidence supporting dual-coding theory, J. Exper. Psychol., Learn., Mem., Cogn. 20 (1994) 804-823.

[24] M. Kutas, Event-related brain potentials (ERPs) elicited during rapid serial visual presentation of congruous and incongruous sentences, Electroencephalogr. Clin. Neurophysiol., Suppl. 40 (1987) 406-411. 
[25] M. Kutas, F.D. Federmeier, Electrophysiology reveals semantic memory use in language comprehension, Trends Cogn. Sci. 4 (2000) 463-470.

[26] M. Kutas, S.A. Hillyard, Brain potentials during reading reflect word expectancy and semantic association, Nature 307 (1984) 161-163.

[27] M. Kutas, V. Iragui, The N400 in a semantic categorization task across 6 decades, Electroencephalogr. Clin. Neurophysiol. 108 (1998) 456-471.

[28] M. Kutas, R. Kluender, What is who violating? A reconsideration of linguistic violations in light of event-related brain potentials, in: H.J. Heinze, T.F. Münte, G.R. Mangun (Eds.), Cognitive Electrophysiology, Birkhäuser, Boston, 1994.

[29] M. Kutas, G. McCarthy, E. Donchin, Augmenting mental chronometry: the P300 as a measure of stimulus evaluation time, Science 197 (1977) $792-795$.

[30] S. Krashen, L. Galloway, The neurological correlates of language acquisition: current research, SPEAQ J. 2 (1978) 21-35.

[31] E. Lenneberg, The biological foundations of language, Hosp. Pract. 2 (1967) 59-67.

[32] E. Mägiste, Recall of concrete and abstract sentences in bilinguals, Scand. J. Psychol. 20 (1979) 179-185.

[33] E.M. Moreno, K.D. Federmeier, M. Kutas, Switching languages, switching palabras (words): an electrophysiological study of code switching, Brain Lang. 80 (2002) 188-207.

[34] T.F. Münte, H.J. Heinze, G.R. Mangun, Dissociation of brain activity related to syntactic and semantic aspects of language, J. Cogn. Neurosci. 3 (1993) 335-344.

[35] H.J. Neville, J.L. Nicol, A. Barss, K.I. Forster, M.F. Garrett, Syntactically based sentence processing classes: evidence from event-related brain potentials, J. Cogn. Neurosci. 3 (1991) $151-165$

[36] R.C. Oldfield, The assessment and analysis of handedness: the Edinburgh inventory, Neuropsychologia 9 (1971) 97-113.

[37] E. Olshtain, M. Barzilay, Lexical retrieval difficulties in adult language attrition, in: H. Seliger, R. Vago (Eds.), First Language Attrition, Cambridge University Press, Cambridge, 1991, pp. 139-151.

[38] A. Paivio, J.M. Clark, W.E. Lambert, Bilingual dual-coding theory and semantic repetition effects on recall, J. Exper. Psychol. Learn. Mem. Cogn. 14 (1988) 163-172.

[39] K.A. Paller, M. Kutas, A.P. Shimamura, L.R. Squire, Brain responses to concrete and abstract words reflect processes that correlate with later performance on test of recall and stem completion priming, in: R. Johnson, J. Rohrbaugh, R. Parasuraman (Eds.), Current Trends in Brain Potential Research, Elsevier, Amsterdam, 1987, pp. $360-365$.
[40] M. Paradis, Language lateralization in bilinguals: enough already!, in: L. Wei (Ed.), The Bilingualism Reader, Routledge, London, 2000 pp. 394-401.

[41] M. Paradis, The bilingual Loch Ness Monster raises its nonasymmetric head again-or, why bother with such cumbersome notions as validity and reliability? Comments on Evans et al. (2002), Brain Lang. 87 (2003) 441-448.

[42] D. Perani, E. Paulesu, N. Sebastian-Galles, E. Dupoux, S. Dehaene, V. Bettinardi, S.F. Cappa, F. Fazio, J. Mehler, The bilingual brain: proficiency and age of acquisition of the second language, Brain 121 (1998) $1841-1852$.

[43] A.M. Proverbio, B. Cok, A. Zani, Electrophysiological measures of language processing in bilinguals, J. Cogn. Neurosci. 14 (2002) 994-1017.

[44] G.J. Rey, A.L. Benton, Multilingual Aphasia Examination-Spanish. Manual of Instructions, AJA Associates, Iowa City, 1991.

[45] D.S. Ruchkin, R. Johnson Jr., H. Canoune, W. Ritter, Short-term memory storage and retention: an event-related brain potential study, Electroencephalogr. Clin. Neurophysiol. 76 (1990) 419-439.

[46] H.B. Shin, R. Bruno, Language use and English-speaking ability: 2000. Census 2000 Brief. U.S. Department of Commerce. Economics and Statistics Administration. U.S. Census Bureau, October 2003.

[47] T.Y. Swaab, K. Baynes, R.T. Knight, Separable effects of priming and imageability on word processing: an ERP study, Cogn. Brain Res. 15 (2002) 99-103.

[48] J.G. Van Hell, A.M.B. De Groot, Conceptual representation in bilingual memory: effects of concreteness and cognate status in word association, Biling. Lang. Cogn. 1 (1998) 193-211.

[49] J.G. Van Hell, A.M.B. De Groot, Disentangling context availability and concreteness in lexical decision and word translation, Q. J. Exp. Psychol., A 51 (1998) 41-63.

[50] C. Van Petten, M. Kutas, The use of event-related potentials in the study of brain asymmetries, Int. J. Neurosci. 39 (1988) 91-99.

[51] H.G. Vaughan Jr., J.C. Arezzo, The neural basis of event-related potentials, in: T.W. Picton (Ed.), Human Event-Related Potentials, Handbook of Electroencephalography and Clinical Neurophysiology. Revised Series, vol. 3, Elsevier, Amsterdam, 1988, pp. 45-96.

[52] C.M. Weber-Fox, H.J. Neville, Maturational constraints on functional specializations for language processing: ERP and behavioral evidence in bilingual speakers, J. Cogn. Neurosci. 8 (1996) 231-256.

[53] L. Wei, Dimensions of bilingualism, in: L. Wei (Ed.), The Bilingualism Reader, Routledge, London, 2000, pp. 3-25.

[54] W.C. West, P.J. Holcomb, Imaginal, semantic, and surface-level processing of concrete and abstract words: an electrophysiological investigation, J. Cogn. Neurosci. 12 (2000) 1024-1037. 